\title{
The Robustness of Poverty Profiles Reconsidered
}

Tarp, Finn; Simler, Kenneth; Matusse, Cristina; Heltberg, Rasmus; Dava, Gabriel

Published in:

Economic Development and Cultural Change

Publication date:

2002

Citation for published version (APA):

Tarp, F., Simler, K., Matusse, C., Heltberg, R., \& Dava, G. (2002). The Robustness of Poverty Profiles Reconsidered. Economic Development and Cultural Change, 51(1). 


\title{
The Robustness of Poverty Profiles Reconsidered*
}

\author{
Finn Tarp \\ University of Copenhagen \\ Kenneth Simler \\ International Food Policy Research Institute \\ Cristina Matusse \\ Ministry of Planning and Finance, Maputo, Mozambique \\ Rasmus Heltberg \\ University of Copenhagen \\ Gabriel Dava \\ Ministry of Planning and Finance, Maputo, Mozambique
}

\section{Introduction}

Poverty reduction is the primary goal of economic development, and there is a long and rich literature on the theory, conceptualization, and measurement of poverty. Yet numerous conceptual and technical issues remain. ${ }^{1}$ The lack of consensus on concepts and methods-and more precisely, the differing results that may arise from different methods-presents a serious challenge for policy makers aiming to allocate scarce resources effectively for poverty reduction. Poverty measures and poverty profiles are used increasingly as guides in targeting resources for poverty reduction, but an allocation that is efficient according to one methodology may prove to be ineffectual under another. Conversely, if different methods produce similar results, policy makers can be more confident that their allocation decisions are robust.

This article examines alternative methods used to set absolute poverty lines for the measurement of consumption poverty. Recent literature has compared the two most common methods for setting poverty lines, the Food Energy Intake (FEI) and the Cost of Basic Needs (CBN) approaches, using the criteria of consistency (treating persons with the same living standards equally) and specificity (using notions of poverty that are applicable to the

(C) 2002 by The University of Chicago. All rights reserved. $0013-0079 / 2003 / 5101-0004 \$ 10.00$ 
communities under consideration). The emerging consensus appears to be that for subgroup comparisons the CBN method is more consistent than the FEI method and is also sufficiently specific. ${ }^{2}$ However, the common practice of specifying a single national food bundle may be inappropriate in settings where the food consumption patterns of the poor are heterogeneous because of differences in the relative prices of staple foods. Data from Mozambique, a large and agroecologically diverse country with extremely poor market integration, are used to test the robustness of different methods for setting the poverty line. We also address a shortcoming of the existing literature, namely, the lack of systematic definition of domains over which a poverty line applies. ${ }^{3}$

Section II examines the methodological aspects of determining poverty lines and briefly makes the case for consistency and specificity of poverty comparisons across subgroups. This is followed by a discussion of data and the Mozambique country context in Section III. Section IV details our methodology for determining the FEI and CBN poverty lines, and Section V presents six sets of poverty lines and estimates of poverty indexes. The characteristics of the poor are compared in Section VI along the lines of standard poverty profiles, followed by an investigation of the factors underlying the differences in poverty comparisons in Section VII. Section VIII summarizes the article and offers concluding comments.

\section{Poverty Line Principles and Practice}

The analysis of absolute poverty has four basic steps in economics. First, the analyst chooses a welfare measure, which is usually household expenditure or income adjusted for the size and composition of the household. Second, a poverty line is set at a level of welfare corresponding to some minimum acceptable standard of living. The poverty line acts as a threshold, where households falling below the poverty line are considered poor and those above the poverty line are considered nonpoor. Third, once the poor have been identified, poverty measures such as the head count ratio, poverty gap, and squared poverty gap are estimated. Fourth, poverty profiles can be constructed, showing how poverty varies over population subgroups (e.g., across regions) or by characteristics of the household (e.g., landowners and the landless). Poverty profiles are important; what matters most to many policy makers is not so much the precise location of the poverty line but the implied poverty comparison across subgroups or across time. ${ }^{4}$

Absolute poverty lines are typically set to represent the expenditure (or consumption or income) required to attain some minimum level of welfare, so the line is meant to reflect the cost of obtaining a given reference level of utility or standard of living that defines the threshold of poverty. Usually the minimum level of welfare is linked to nutritional requirements, supplemented by an allowance for basic nonfood needs. The poverty line can, therefore, be thought of as a deflator that translates the nominal value of welfare into real terms and establishes the comparability of the welfare measure across the population under study. ${ }^{5}$ When the welfare measure is expressed in real terms, 
an assessment of the robustness of alternative poverty lines can be made by plotting the cumulative density functions (or integrals thereof) of relevant subgroups and testing for welfare dominance over a range of relevant poverty lines. ${ }^{6}$ The robustness we consider here is fundamentally different. Rather than testing for dominance in a relevant range of the given real welfare distributions, we go one step back in the process to examine the way in which the choice of poverty lines affects the shape of the welfare distribution itself. ${ }^{7}$

There are four major methods for setting absolute poverty lines: the FEI approach, the CBN approach, the one-dollar-a-day criterion used for international comparisons by the World Bank and others, and a social subjective poverty line. In this article, we concentrate on an assessment of the consistency and specificity of the FEI and CBN methods. ${ }^{8}$

The FEI approach associates the poverty line with the monetary value of the total expenditure or income for an average (or representative) household that just manages to meet stipulated caloric requirements. ${ }^{9}$ It is common practice to derive the FEI poverty line from the parameters estimated in a regression of the relationship between energy intake and expenditure or income. Functional forms vary, and energy intake may appear on the right-hand or the left-hand side (with expenditure or income on the other). The analysis can be carried out on a per capita or an adult-equivalent basis. The FEI approach can be estimated on the basis of a national sample to generate a single national poverty line, but, in practice, a disaggregated approach is usually chosen to estimate separate rural and urban FEI lines or even regional or provincial lines. ${ }^{10}$ The actual consumption baskets of the poor are implicit in the FEI poverty line(s) and are based on observed behavior, in response to prices, by the group of households around the predetermined caloric threshold. Thus, a major advantage of the FEI approach is its specificity. Another advantage is simplicity-FEI establishes in a straightforward manner the level of expenditure or income at which a typical household meets its nutritional requirements.

The CBN method, focused on ensuring consistent welfare comparisons, is also based on nutritional requirements. It identifies a basic food bundle from the data that is consistent with the consumption patterns of persons who are perceived to be poor, scales the quantities in this bundle up or down to correspond to nutritional requirements, and calculates the cost of acquiring the basket that results from the previous two steps. Subsequently, a nonfood poverty line is calculated, for example, by estimating the cost of consuming a basic set of nonfood goods and services or by estimating the average nonfood budget share of the relatively poor (in each subgroup). The sum of the food and nonfood poverty lines is the total poverty line, from which poverty measures and comparisons are derived.

The consumption bundles (implicit in FEI, explicit in CBN) are based on observed consumption patterns. Moreover, to be considered nonpoor, a household or an individual is neither required to consume the specific items in the bundle nor to consume the minimum number of calories on which the poverty line is based. As such, both the FEI and CBN methods of setting 
poverty lines are attempts to measure consumption poverty, not undernutrition. Despite these similarities, the FEI and CBN approaches and their different versions can generate vastly different poverty lines and yield contradictory poverty profiles. The trade-off faced is between the specificity of the FEI approach and the strength of the CBN approach, which is consistency.

Using Indonesian data, Martin Ravallion and Benu Bidani found zero correlation between the poverty comparisons generated by the selected FEI and CBN methods (the FEI results were based on separate lines for the rural and the urban subgroups, while CBN used a single national bundle and 50 region-specific price vectors). ${ }^{11}$ They also compared the average consumption of households in the vicinity of an FEI poverty line in rural and urban areas. Although both contained approximately 2,100 calories per capita, the average urban diet had more rice, expensive vegetables, meat, food, and drink outside of the home and less cheap staple foods than the average rural diet of people in the vicinity of the rural FEI line. The urban poverty line was sufficient to acquire a consumption bundle that almost all Indonesians would prefer relative to the rural bundle. Ravallion and Bidani conclude that the CBN estimates yield more consistent poverty comparisons across subgroups and are, therefore, preferable. Ravallion and Binayak Sen and Quentin Wodon arrive at similar conclusions in analyses of poverty in Bangladesh. ${ }^{12}$

It is not uncommon for analyses based on the disaggregated FEI approach, in which separate urban and rural poverty lines are set, to indicate higher poverty in urban than in rural areas. At a given level of income, urban households tend to consume fewer-but more expensive (higher quality) — calories than rural households. This will push the urban poverty line higher than can be justified on welfare grounds. Applying the FEI approach to generate a single national poverty line does not resolve the problem and may result in the opposite situation. Whenever food is relatively cheaper in rural areas, as is usually the case, a single nominal poverty line underestimates urban poverty relative to rural poverty. These shortcomings of the FEI approach, which lead to potentially inconsistent poverty comparisons across subgroups, are by now fairly well known. The issue of the CBN methodology and its potential problems in making subgroup comparisons has drawn less attention, however.

From the discussion above, it is clear that consistency is a desirable characteristic when setting poverty lines. In this context, consistency means that two individuals at the same level of welfare should be treated identically. ${ }^{13}$ To put it differently, "whether or not a given standard of living constitutes poverty should not depend on the subgroup to which the person with that standard of living belongs. ${ }^{\prime 14}$ If the monetary cost of attaining a given minimum level of welfare is higher in region A than in region B, the poverty line for region A should be correspondingly higher than the poverty line of region $\mathrm{B}$. This is an important consideration in settings where the prices of basic goods vary spatially or temporally and highlights the role of the poverty line as a price index.

One common method of attempting to ensure consistency is the use of 
TABLE 1

Illustrative Example of Inconsistency of CBN Fixed-Bundle Food Poverty Lines

\begin{tabular}{ccrrrr}
\hline & $\begin{array}{c}\text { Cost per } \\
\text { Calorie }\end{array}$ & $\begin{array}{c}\text { Calories } \\
\text { Consumed }\end{array}$ & $\begin{array}{c}\text { Total } \\
\text { Expenditure }\end{array}$ & $\begin{array}{c}\text { CBN-1 } \\
\text { Bundle } \\
\text { (Calories) }\end{array}$ & $\begin{array}{c}\text { CBN-1 } \\
\text { Food Poverty } \\
\text { Line }\end{array}$ \\
\hline Region A: & & & & & \\
Cassava & 1 & 1,500 & 1,500 & 750 & 750 \\
Maize & 2 & 0 & 0 & 750 & 1,500 \\
Beans & 1 & 500 & 500 & 500 & 500 \\
\cline { 2 - 6 } Total & & 2,000 & 2,000 & 2,000 & 2,750 \\
Region B: & 3 & 0 & 0 & 750 & 2,250 \\
Cassava & 1 & 1,500 & 1,500 & 750 & 750 \\
Maize & 1 & 500 & 500 & 500 & 500 \\
Beans & 1 & 2,000 & 2,000 & 2,000 & 3,500 \\
Total & & & & & \\
\hline
\end{tabular}

a single consumption bundle throughout a country, only allowing the poverty line to vary because of differences in the price level encountered by different subgroups. However, using the same bundle across subgroups does not guarantee comparability of welfare levels. As observed by Joel Greer and Erik Thorbecke, a given "poverty line is valid only if it refers to a group of households sharing similar food preferences and facing uniform prices." 15

If relative prices are not uniform, the CBN method with a single national bundle (CBN-1 for short) can generate inconsistent poverty comparisons. For an illustrative example-without loss of generality — consider two regions that have the same distribution of welfare and are, therefore, equally poor. The populations of the two regions are of the same size and composition, and consumption preferences of the poor in the two regions are identical. The poor consume three food items: maize, cassava, and beans. In this stylized example, maize and cassava are perfect substitutes in consumption, and beans are a complementary food item. The salient difference between the two regions is the relative prices of maize and cassava. In region A, we assume maize is twice as expensive as cassava, whereas in region B cassava is three times the price of maize; the price of beans relative to the cheaper staple is the same in each region. In keeping with standard CBN food poverty line practice, these are expressed as the cost of a calorie from each source.

Table 1 shows the arithmetic of this example. Given the identical preferences but differing relative prices described above, we see that poor households in region A get 1,500 calories per day from cassava, 500 from beans, and none from maize. Consumption in region B is the same, except that the roles of cassava and maize are reversed. In both regions, the total outlay required to consume the food bundle relevant to the poor is 2,000 units of the national currency. The last two columns of the table show the quantities and values of the associated fixed-bundle CBN food poverty lines for the two regions. The food quantities in the $\mathrm{CBN}-1$ bundles are simply the mean values 
of the consumption of each item in the two regions; the bundle provides 2,000 calories.

We note, however, that in the final column the food poverty line in region $\mathrm{B}$ is $25 \%$ higher than that in region A. ${ }^{16}$ Despite the identical welfare distributions of the two regions, region $\mathrm{B}$ will appear to be poorer in poverty comparisons solely because of the relatively high price of cassava in region $\mathrm{B}$, even though cassava is not consumed by the poor in that region. This result is not dependent on achieving the corner solution described here; the perfect substitutability assumption does not drive the result-it merely simplifies the exposition.

The need to ensure consistency in the treatment of bundles consumed across subgroups leads directly to the criterion that poverty lines should reflect local perceptions of what constitutes poverty, or what Ravallion and Bidani refer to as specificity. ${ }^{17}$ Specificity requires that a locally irrelevant basket of goods should not be imposed. In the words of Ravallion and Bidani, "specificity may be interpreted as either a separate goal of basic needs consistency or as another way to define consistency, by which the measure of individual well being is broadened to include feelings of relative deprivation." ${ }^{18}$

Thus, allowing bundles to vary across subgroups runs the risk that the welfare of the relatively poor in each subgroup is not identical, resulting in inconsistent comparisons. The danger of the opposite, a uniform bundle, is that this basket may be locally irrelevant, which can also generate inconsistent comparisons. Striking the right balance between the need for consistency and specificity is, therefore, far from easy. The appropriate balance will depend on the heterogeneity of the country in question as well as on the particular purpose of the analysis.

While the direction of the rural or urban biases inherent in the FEI approach appears well understood, this cannot be said in general for the CBN method. Here the direction of the bias is unknown. Standard CBN practice as applied by Ravallion and Bidani, World Bank, and Wodon is to rely on one national (or fixed) food bundle that is multiplied by price vectors that are specific to the subgroups (regions) considered. ${ }^{19}$ Variations in the estimated regional poverty lines are, therefore, solely a function of price differences. Yet, according to Ravallion and Sen, "while the (implicit) bundle of goods in the FEI method [i.e., with a rural and urban distinction] almost certainly varies too much to be consistent with the same standard of living, the (explicit) bundle in the CBN method varies too little." ${ }^{20}$ Furthermore, the basis used for assessing the FEI and CBN approaches in Ravallion and Bidani and in Wodon appears problematic. ${ }^{21}$ The FEI estimates based on separate urban and rural poverty lines are compared with $\mathrm{CBN}$ estimates based on one national bundle evaluated at subgroup price vectors. A more complete set of comparisons of the two methods is called for and, indeed, motivates this article.

When relative prices differ across regions, it is perfectly reasonable for a poor household in one region to consume a different basic needs bundle than an equally poor household in another region. What is not acceptable is 
for the differences in poverty lines to reflect differences in standards of living, as would be the case if poor households in region A preferred the basic needs bundle in region $B$ to their own basic needs bundle. One potentially attractive and transparent approach of trying to deal with these problems that has not been applied widely so far is to make use of the multiple bundle version of the CBN methodology in which both bundles and prices vary by subgroup. ${ }^{22}$ There would seem to be a priori justification for the use of the multiple bundle approach in countries with poorly integrated food markets. If substitution effects are significant, the imposition of a fixed bundle will distort regional welfare comparisons. If substitution effects are not significant, the multiple bundle approach should collapse to a single national bundle.

\section{Data and Country Context}

The household level data used in this article come from the Mozambique "Inquérito nacional aos agregados familiares sobre as condições de vida" (National household survey of living conditions; known by the abbreviation IAF). The survey was conducted by the Instituto Nacional de Estatística (National Institute of Statistics; INE) during February of 1996 through April of 1997, and it is the first nationally representative household survey in Mozambique. Coverage and quality of this data set is comparable to the World Bank-sponsored Living Standard Measurement Study (LSMS) surveys conducted in many countries. ${ }^{23}$ The survey uses a stratified three-stage cluster sampling design, is intended to be representative at the provincial level, and supports subdivision by rural and urban areas of residence. The sample is made up of 42,180 individuals living in 8,250 households. All standard errors reported in this article take account of the complex sample design by using the variance estimators available in the survey analysis routines of the statistical software package Stata. ${ }^{24}$

Mozambique is one of the poorest countries in the world. It is a large and agroecologically diverse country spanning almost 2,000 kilometers from north to south. The northern and central provinces tend to be more fertile than the south. Humidity and rainfall also vary greatly. In the south, average annual rainfall is only about 600 millimeters, whereas rainfall in the central region and throughout the north is much higher, between 1,000 and 1,800 millimeters. Adverse climatic conditions, defined as a climate outcome producing a greater than $25 \%$ decline in maize yields relative to the most likely of five climate scenarios, have been estimated to occur 18\%, 30\%, and 63\% of the time in the north, center, and south of Mozambique, respectively. ${ }^{25}$

Three million farm households, living in dispersed settlements throughout the country, dominate the agricultural sector. The total population at the time of the last census in August 1997 was 16.1 million, of whom more than 70\% live in rural areas. ${ }^{26}$ Population density is 20 people per square kilometer on average, ranging from 37.5 people per square kilometer in the province of Nampula to less than six people per square kilometer in Niassa in the north. The poor state of infrastructure, particularly in rural areas, affects economic 
and social life in a variety of ways. Transportation costs are high, and some regions are isolated. Markets are poorly developed as a consequence of the colonial heritage, command economy economic policies pursued after independence in the mid-1970s, and the war that devastated the country during the 1980s and early 1990s. While some improvement has taken place in recent years, it is concentrated in the southern part of the country, and the country is rebuilding from an extremely low starting point.

There are substantial differences in production and consumption patterns across the 10 provinces that make up Mozambique. The production pattern reflects, in part, the diverse agroecological conditions. In addition, because of high marketing margins and the lack of market integration, rural households often consume a large proportion of their own production. Average domestic marketing costs for cassava amount to $80 \%$ of market prices, while maize margins are much lower, at around $25 \%$, but substantial regional variation exists.

While cassava and maize are the two key staple crops, their importance in production and consumption also varies drastically across regions. Maize is a marketable crop that is found in production and consumption patterns throughout Mozambique. By contrast, in some areas cassava is almost nonexistent, whereas elsewhere it dominates. In addition to the widely varying agroecological and marketing conditions already noted, interactions between agricultural technology, risk, and gender also play significant roles. ${ }^{27}$

When one considers the extreme diversity and lack of integration of the Mozambican economy, it is hardly surprising that there are large spatial differences in absolute and relative prices. These differences should be taken into account to provide a true picture of the distribution of poverty. This is particularly relevant to policy makers, who are rightly concerned about the need to reduce existing asymmetries and disparities across the different parts of the country. ${ }^{28}$ They should be alert to the robustness of conclusions emerging from applying different methodologies for poverty assessment.

\section{Methodology}

In this section, we describe in detail the steps taken in establishing each set of poverty lines used. Six sets of poverty lines are considered, employing the two basic methods (FEI and CBN) at three different levels of aggregation. They correspond in the FEI approach to the number of unique poverty lines, whereas they reflect the distinct number of food bundles used for the CBN poverty lines. The three levels of aggregation, or specificity, are (1) national, (2) rural and urban area of residence, and (3) 13 geographic regions delineated by rural and urban area of residence and provincial boundaries. For convenience, the six sets of poverty lines will be referred to as FEI-1, FEI-2, FEI$13, \mathrm{CBN}-1, \mathrm{CBN}-2$, and $\mathrm{CBN}-13$.

The variable for total consumption per capita in nominal terms is the same throughout for each household. The total consumption measure includes purchases and home consumption of food items, purchases of nonfood goods 
TABLE 2

Distribution of Sample Households by Poverty Line Domains

\begin{tabular}{lcc}
\hline Spatial Domain & $\begin{array}{c}\text { Number of } \\
\text { Households }\end{array}$ & \% of Total Sample \\
\hline Niassa and Cabo Delgado (rural) & 1,186 & 14.4 \\
Niassa and Cabo Delgado (urban) & 214 & 2.6 \\
Nampula (rural) & 719 & 8.7 \\
Nampula (urban) & 236 & 2.9 \\
Sofala and Zambézia (rural) & 1,301 & 15.8 \\
Sofala and Zambézia (urban) & 345 & 4.2 \\
Manica and Tete (rural) & 987 & 12.0 \\
Manica and Tete (urban) & 285 & 3.5 \\
Gaza and Inhambane (rural) & 1,187 & 14.4 \\
Gaza and Inhambane (urban) & 179 & 2.2 \\
Maputo Province (rural) & 431 & 5.2 \\
Maputo Province (urban) & 287 & 3.5 \\
Maputo City & 893 & 10.8 \\
$\quad$ Total & 8,250 & 100.0 \\
\hline
\end{tabular}

Note. - The poverty line domains are those regions used to construct separate poverty lines, thereby partially controlling for spatial differences in prices and household composition.

and services, and imputed use values for household durables and owneroccupied housing. ${ }^{29}$ Monetary values for food consumption were adjusted to take temporal price variation into account, using available market price information corresponding to the survey period. ${ }^{30}$

Defining areas as rural or urban follows the classification used in the sample design of the IAF survey. ${ }^{31}$ The city of Maputo, all provincial capitals, and other selected urban areas make up the urban stratum. The 13 regions were defined based on the principles of grouping areas in which food prices and the food consumption patterns of the poor are similar while maintaining an adequate sample size. The regions and the number of sample households in each are shown in table 2.

The calorie requirements used are the same for each set of poverty lines. They were based on a study by the World Health Organization, taking into account differences in age and sex as well as the pregnancy and lactation status of women. ${ }^{32}$ Moderate activity levels and body mass are assumed. Given the demographic composition of Mozambique's population, requirements average approximately 2,150 kilocalories per person per day.

Food Energy Intake (FEI)

For the FEI poverty lines, we ran regressions of the form $\ln (y)=a+$ $b C+e$, where $y$ is daily per capita consumption, $C$ is calories consumed, and $e$ is the disturbance term. The FEI poverty lines correspond to the level of expenditure per capita at which caloric intake is equal to the recommended daily caloric requirements per capita. Thus, the poverty lines are calculated as $z_{k}^{\mathrm{FEI}}=\exp \left(\hat{a}_{k}+C_{k}^{*} \hat{b}_{k}\right)$, where $\hat{a}$ and $\hat{b}$ are the parameter estimates, $C^{*}$ is 
TABLE 3

Food Energy Intake (FEI) Regression Results

\begin{tabular}{|c|c|c|c|c|}
\hline Method and Domain & Slope Coefficient & Intercept & $N$ & $R^{2}$ \\
\hline \multicolumn{5}{|l|}{ FEI-1: } \\
\hline National & $.261(20.75)^{* *}$ & $.884(25.07) * *$ & 6,048 & .16 \\
\hline \multicolumn{5}{|l|}{ FEI-2: } \\
\hline Urban & $.381(11.34)^{* *}$ & $1.177(12.61)^{* *}$ & 1,849 & .23 \\
\hline Rural & $.228(19.02)^{* *}$ & $.814(25.35)^{* *}$ & 4,150 & .18 \\
\hline \multicolumn{5}{|l|}{ FEI-13: } \\
\hline \multicolumn{5}{|l|}{ Rural Niassa and Cabo } \\
\hline Delgado & $.211(6.83)^{* * *}$ & $.670(6.74) * *$ & 824 & .19 \\
\hline \multicolumn{5}{|l|}{ Urban Niassa and Cabo } \\
\hline Delgado & $.235(4.22)^{* *}$ & $1.039(9.30)^{* *}$ & 149 & .15 \\
\hline Rural Nampula & $.241(10.80)^{* *}$ & $.430(5.95)^{* *}$ & 514 & .25 \\
\hline Urban Nampula & $.379(3.40)^{*}$ & $.553(3.64)^{*}$ & 178 & .28 \\
\hline \multicolumn{5}{|l|}{ Rural Sofala and } \\
\hline Zambézia & $.341(17.85)^{* *}$ & $.664(17.08)^{* * *}$ & 875 & .42 \\
\hline \multicolumn{5}{|l|}{ Urban Sofala and } \\
\hline Zambézia & $.267(4.87)^{* *}$ & $1.325(12.21)^{* *}$ & 278 & .16 \\
\hline Rural Manica and Tete & $.295(9.31)^{* *}$ & $.632(8.68)^{* *}$ & 711 & .27 \\
\hline Urban Manica and Tete & $.279(6.79)^{* * *}$ & $1.273(13.88) * *$ & 191 & .22 \\
\hline \multicolumn{5}{|l|}{ Rural Gaza and } \\
\hline Inhambane & $.319(12.73)^{* *}$ & $.992(16.69)^{* *}$ & 950 & .27 \\
\hline \multicolumn{5}{|l|}{ Urban Gaza and } \\
\hline Inhambane & $.459(4.14)^{*}$ & $1.269(7.47)^{* *}$ & 138 & .20 \\
\hline Rural Maputo Province & $.319(11.58)^{* *}$ & $1.194(19.42)^{* *}$ & 316 & .27 \\
\hline Urban Maputo Province & $.014(-.36)$ & $2.082(16.45)^{* *}$ & 172 & .001 \\
\hline Maputo City & $.472(15.25)^{* *}$ & $1.311(17.09)^{* *}$ & 768 & .34 \\
\hline
\end{tabular}

NotE. - Robust $t$-statistics in parentheses. Dependent variable: natural $\log$ of total daily consumption per capita/1,000 Mozambican meticais. Independent variable: daily calorie consumption per capita per 1,000 .

* Significant at the 5\% level.

** Significant at the $1 \%$ level.

the calorie requirement, and $k$ indexes the region. ${ }^{33}$ The regression approach and functional form follow those of Joel Greer and Erik Thorbecke. ${ }^{34}$ Results are shown in table 3, with good fits in all cases except for FEI-13 in urban Maputo Province. Compared with Greer and Thorbecke, three special features in our estimation deserve mention. First, we use total consumption rather than food consumption as the welfare indicator. Second, we exclude influential observations based on a DFBETA criterion. ${ }^{35}$ Third, we do the entire analysis on per capita terms to maintain comparability between the FEI and the CBN poverty lines. Experiments with calorie intake per adult equivalent unit produced similar results. ${ }^{36}$ Because the FEI method relates calorie intake to total consumption, an allowance for nonfood consumption is automatically included.

Cost of Basic Needs $(C B N)$

For all of the CBN poverty lines estimated here, the poor were defined as those households whose per capita calorie consumption was below the rec- 
ommended minimum requirement of approximately 2,150 kilocalories per person. A more conventional practice is to use the consumption patterns of those households whose total consumption in nominal terms is below a certain level, which serves as a "first guess" of the poverty line, and then to iterate. ${ }^{37}$ For the $\mathrm{CBN}-1$ and $\mathrm{CBN}-2$ poverty lines, a group of 23 food items was selected for the food bundle, including all items that made significant contributions to total caloric intake. Over most of the country, these items account for $73 \%$ to $96 \%$ of calorie consumption of the relatively poor. The only exception is the city of Maputo, where these 23 items contribute $65 \%$-still a large share-of the calorie consumption of the poor. In all areas, the remainder of calorie intake comes from small contributions of up to 100 different food items. These are necessarily excluded from the CBN-1 and CBN-2 food bundles because of the practical problem of including a food item in the bundle for which there is no observed corresponding price in a given region. However, they are included in the CBN-13 food bundles; at this higher level of spatial disaggregation, consumption of these items is always observed with a corresponding price or unit value.

Regardless of the level of specificity of the food bundle, region-specific unit values are used throughout to calculate the cost of acquiring the food bundle, which defines the CBN food poverty line. Allowing prices to vary by region is, by now, common practice in CBN analyses. ${ }^{38}$ The household survey provides information on the quantity and value of all foods consumed, whether from market purchases, home production, transfers, payment in kind, or any other source. The quantities in grams are readily converted to calorie equivalents using food nutrient tables. From these food consumption data, the calorie-weighted mean price paid per calorie (unit value) was calculated within each region for each item in the food bundle. This is equivalent to calculating the region-specific mean unit value of a "composite" calorie, with the weights of the composite calorie determined by the actual consumption patterns of the poor. ${ }^{39}$

As the calorie consumption of the poor is less than the recommended minimum, the cost of acquiring the food bundle must be scaled up to the level of calorie requirements. We therefore increased the quantities of each item in the bundle proportionally so that the calorie requirement is satisfied and the calorie shares from each item in the bundle are preserved. To put it slightly differently, the mean cost of a composite calorie is multiplied by the calorie requirement to obtain the region-specific food poverty line.

The construction of the CBN food poverty lines may be summarized as follows:

CBN-1:

$$
z_{k}^{F}=\sum_{i=1}^{23} p_{i k} q_{i}
$$


CBN-2:

$$
z_{k}^{F}=\sum_{i=1}^{23} p_{i k} q_{i j}
$$

CBN-13:

$$
z_{k}^{F}=\sum_{i=1}^{N} p_{i k} q_{i k}
$$

where $z_{k}^{F}$ is the CBN food poverty line in region $k, p_{i k}$ is the average unit value (price) of a calorie of commodity $i$ in region $k, q_{i}$ is the quantity of calories that commodity $i$ contributes to the food bundle (already scaled to requirements), $j$ indexes rural or urban area of residence, and $k$ indexes the 13 regions shown in table 2 . The number $(N)$ of food items included in the food bundle is fixed at 23 for CBN-1 and CBN-2.

An allowance for nonfood basic needs was derived by nonparametrically estimating the mean nonfood expenditure of those households whose total consumption is in the neighborhood (plus or minus 20\%) of the food poverty line. ${ }^{40}$ The nonfood poverty line was allowed to vary by the 13 regions.

Finally, in this study, as in the literature more generally, the FEI and CBN methodologies focus on different subsamples when estimating the link between total consumption and calorie intake. The FEI method typically uses the entire sample of households in a regression framework. The CBN approach, on the other hand, focuses exclusively on those considered to be poor according to some criterion, such as nominal total consumption or calorie intake, and explicitly ignores the upper part of the distribution. These differences, as suggested in Section II, are likely to lead to systematic differences in poverty lines because at higher incomes people will tend to buy more expensive calories. This has no impact on the CBN calculation but might bias upward the FEI estimates of poverty lines and poverty indexes, particularly when subgroup disaggregation is allowed.

Poverty statistics are calculated using a subset of the standard FosterGreer-Thorbecke (FGT) $P_{\alpha}$ class of poverty measures. ${ }^{41}$ This family of poverty measures is defined as

$$
P_{\alpha}=\frac{1}{n} \sum_{y \leq z}(1-y / z)^{\alpha},
$$

where $y$ is consumption (or income), $z$ the poverty line, and $n$ total population. We work with $\alpha=0,1,2$, corresponding to the head count, the poverty gap, and the squared poverty gap measures, respectively.

\section{Poverty Lines and Indexes}

In this section, we review results, summarize the estimates of poverty indexes, and examine changes in regional poverty rankings. We also compare the poverty estimates to a variety of nonmonetary welfare indicators. The natural 
TABLE 4

Cost of Basic Needs (CBN) Food Poverty Lines for Mozambique

\begin{tabular}{lccc}
\hline & \multicolumn{3}{c}{ MetiCAIS PER PERSON PER DAY } \\
\cline { 2 - 4 } REGION & CBN-1 & CBN-2 & CBN-13 \\
\hline Rural Niassa and Cabo Delgado & 4,342 & 4,108 & 3,011 \\
Urban Niassa and Cabo Delgado & 7,134 & 6,465 & 3,687 \\
Rural Nampula & 4,029 & 3,794 & 2,742 \\
Urban Nampula & 4,087 & 4,560 & 3,642 \\
Rural Zambézia and Sofala & 4,975 & 4,836 & 3,719 \\
Urban Zambézia and Sofala & 4,874 & 5,025 & 5,370 \\
Rural Tete and Manica & 3,929 & 3,678 & 3,845 \\
Urban Tete and Manica & 5,070 & 5,421 & 5,548 \\
Rural Gaza and Inhambane & 8,215 & 8,377 & 4,971 \\
Urban Gaza and Inhambane & 8,037 & 7,802 & 5,714 \\
Rural Maputo Province & 6,790 & 6,894 & 5,418 \\
Urban Maputo Province & 6,717 & 7,201 & 6,047 \\
Maputo City & 7,814 & 6,576 & 6,192 \\
& & & \\
Rural mean & 5,111 & 4,979 & 3,702 \\
Urban mean & 6,254 & 6,000 & 5,253 \\
National mean & 5,344 & 5,187 & 4,018 \\
\hline
\end{tabular}

starting point is the food poverty lines. The CBN food poverty lines are shown in table 4 (as applied here, the FEI methodology does not generate separate food and nonfood poverty lines). They suggest that the cost per calorie, and thereby the food poverty lines, tends to decrease as the number of subgroups over which the bundle is allowed to vary increases. Moving from a fixed national bundle $(\mathrm{CBN}-1)$ to separate rural and urban bundles $(\mathrm{CBN}-2)$, the change is limited. Under the CBN-13 approach, the food poverty lines fall relative to the $\mathrm{CBN}-1$ in 11 of the 13 regions, and the national average drops by a significant $25 \%$.

There are good reasons for this. Imposing a uniform national bundle across regions leads to a basket that does not minimize consumer costs for a given level of utility. However, it is crucial that the estimated differences in the cost of the regional bundles (when moving from one aggregation level to another) are caused only by substitution effects. Otherwise, the multiple-bundle approach will be inconsistent. By and large, this does not appear to be the case in any problematic way when moving from the CBN1 to the $\mathrm{CBN}-13$ approach. The estimated CBN-13 poverty lines correspond quite well to the known "stylized fact" about the Mozambican economy. Maputo City has relatively high costs of living, and the same goes for other urban, as compared with rural, areas. Nevertheless, there are relatively modest increases in two urban food poverty lines, when moving from $\mathrm{CBN}-1$ to $\mathrm{CBN}-13$, caused by a higher prevalence of relatively expensive calories in the regional food bundles. This may be at odds with the requirement that welfare remains comparable and is a warning that inconsistency cannot be completely ruled out. This potential problem is more pronounced when 
TABLE 5

Food Energy Intake (FEI) and Cost of Basic Needs (CBN) Total Poverty Lines

\begin{tabular}{|c|c|c|c|c|c|c|}
\hline \multirow[b]{2}{*}{ REGION } & \multicolumn{6}{|c|}{ Meticais per Person per Day } \\
\hline & FEI-1 & FEI-2 & FEI-13 & $\mathrm{CBN}-1$ & $\mathrm{CBN}-2$ & $\mathrm{CBN}-13$ \\
\hline \multicolumn{7}{|l|}{ Rural Niassa and Cabo } \\
\hline Delgado & 4,253 & 3,693 & 3,078 & 5,807 & 5,442 & 4,023 \\
\hline \multicolumn{7}{|l|}{ Urban Niassa and Cabo } \\
\hline Delgado & 4,253 & 7,439 & 4,648 & 10,051 & 9,138 & 5,434 \\
\hline Rural Nampula & 4,253 & 3,693 & 2,587 & 4,785 & 4,499 & 3,359 \\
\hline Urban Nampula & 4,253 & 7,439 & 3,914 & 5,857 & 6,481 & 4,949 \\
\hline \multicolumn{7}{|l|}{ Rural Zambézia and } \\
\hline Sofala & 4,253 & 3,693 & 4,071 & 6,537 & 6,333 & 4,854 \\
\hline \multicolumn{7}{|l|}{ Urban Zambézia and } \\
\hline Sofala & 4,253 & 7,439 & 6,719 & 6,954 & 7,159 & 7,600 \\
\hline Rural Tete and Manica & 4,253 & 3,693 & 3,506 & 4,819 & 4,500 & 4,713 \\
\hline Urban Tete and Manica & 4,253 & 7,439 & 6,541 & 6,670 & 7,225 & 7,414 \\
\hline \multicolumn{7}{|l|}{ Rural Gaza and } \\
\hline Inhambane & 4,253 & 3,693 & 5,342 & 10,808 & 11,025 & 6,433 \\
\hline \multicolumn{7}{|l|}{ Urban Gaza and } \\
\hline Inhambane & 4,253 & 7,439 & 9,606 & 11,175 & 10,925 & 7,827 \\
\hline Rural Maputo Province & 4,253 & 3,693 & 6,491 & 9,211 & 9,375 & 7,316 \\
\hline Urban Maputo Province & 4,253 & 7,439 & 8,275 & 9,545 & 10,215 & 8,714 \\
\hline Maputo City & 4,253 & 7,439 & 10,570 & 11,032 & 9,145 & 8,541 \\
\hline Rural mean & 4,253 & 3,693 & 3,847 & 6,595 & 6,413 & 4,759 \\
\hline Urban mean & 4,253 & 7,439 & 7,526 & 8,799 & 8,403 & 7,297 \\
\hline National mean & 4,253 & 4,455 & 4,595 & 7,043 & 6,818 & 5,276 \\
\hline
\end{tabular}

moving from the $\mathrm{CBN}-1$ to the $\mathrm{CBN}-2$ approach, where food poverty lines increase in six of 13 cases.

The total poverty lines for all six estimation methods are presented in table 5. With the same two exceptions as before, the regional CBN-1 total poverty lines are higher than the corresponding $\mathrm{CBN}-13$ regional poverty lines. Poverty lines also appear to increase from north to south and from rural to urban regions in a reasonable way. Food is normally more expensive in the urban areas as compared with rural areas because of marketing costs, and the same goes for food that moves from north to south. The cost of nonfood basic needs is also greater in urban areas, and the nonfood budget share of the relatively poor is substantially higher in the towns. This rural and urban difference in living costs is not captured well in the FEI approach. Under FEI-1, the same poverty line is implausibly imposed in both rural and urban areas. Under FEI-2 and FEI-13, the rural and urban differentiation in poverty lines expands so that, on average, the urban lines become $99 \%$ and $93 \%$ higher, respectively, than the rural. This degree of differentiation is equally questionable. From the CBN poverty lines, the implied differences in the average urban costs of living, relative to rural, are $33 \%, 31 \%$, and $53 \%$, all of which would appear to be inside the plausible range. 
TABLE 6

National Level Poverty Estimates under Different Poverty Lines

\begin{tabular}{lcccccc}
\hline Estimate & FEI-1 & FEI-2 & FEI-13 & CBN-1 & CBN-2 & CBN-13 \\
\hline & .596 & .581 & .589 & .820 & .802 & .694 \\
Head count $\left(P_{0}\right)$ & $(.014)$ & $(.013)$ & $(.013)$ & $(.009)$ & $(.009)$ & $(.011)$ \\
& .239 & .227 & .223 & .410 & .395 & .293 \\
Poverty gap $\left(P_{1}\right)$ & $(.008)$ & $(.008)$ & $(.007)$ & $(.008)$ & $(.008)$ & $(.008)$ \\
& .124 & .118 & .111 & .245 & .234 & .156 \\
Squared poverty gap $\left(P_{2}\right)$ & $(.005)$ & $(.006)$ & $(.005)$ & $(.006)$ & $(.006)$ & $(.006)$ \\
\hline
\end{tabular}

NotE.-Standard errors are in parentheses, adjusted for stratified cluster sample design.

TABLE 7

Rural and Urban Poverty Estimates under Different Poverty Lines

\begin{tabular}{lcccccc}
\hline Estimate & FEI-1 & FEI-2 & FEI-13 & CBN-1 & CBN-2 & CBN-13 \\
\hline Rural head count $\left(P_{0}\right)$ & .660 & .575 & .579 & .852 & .835 & .712 \\
& $(.013)$ & $(.014)$ & $(.015)$ & $(.008)$ & $. .009)$ & $(.012)$ \\
& .345 & .605 & .630 & .697 & .672 & .620 \\
Urban head count $\left(P_{0}\right)$ & $(.035)$ & $(.029)$ & $(.025)$ & $(.024)$ & $(.024)$ & $(.027)$ \\
& .266 & .212 & .213 & .430 & .414 & .299 \\
Rural poverty gap $\left(P_{1}\right)$ & $(.008)$ & $(.008)$ & $(.008)$ & $(.008)$ & $. .008)$ & $(.008)$ \\
& .134 & .284 & .260 & .331 & .319 & .267 \\
Urban poverty gap $\left(P_{1}\right)$ & $(.019)$ & $(.023)$ & $(.017)$ & $(.019)$ & $(.020)$ & $(.018)$ \\
& .138 & .104 & .105 & .258 & .246 & .159 \\
Rural $P_{2}$ & $(.006)$ & $(.005)$ & $(.005)$ & $(.007)$ & $. .007)$ & $(.006)$ \\
Urban $P_{2}$ & .071 & .170 & .137 & .194 & .189 & .146 \\
& $(.013)$ & $(.018)$ & $(.013)$ & $(.015)$ & $(.016)$ & $(.014)$ \\
\hline
\end{tabular}

NoTE. - Standard errors are in parentheses, adjusted for stratified cluster sample design.

Poverty Estimates and Comparisons

National level estimates of the poverty head count, poverty gap, and squared poverty gap are presented in table 6 for each of the poverty lines. Poverty is high in Mozambique, ranging from 58\% to $82 \%$ of the population. CBN-1 produces the highest poverty levels, while FEI-2 and FEI-13 yield the lowest head counts. Similar observations apply to the depth and severity of poverty. In table 7 , the poverty measures are shown for each set of poverty lines, disaggregated by urban and rural area of residence. Results are clearly not robust to the choice of poverty line approach. All of the CBN estimates indicate that the incidence, depth, and severity of poverty are greater in rural than in urban areas, and this is statistically significant. Based on FEI-1, we reach the same conclusion, but rural and urban differences in poverty appear to be much larger. Yet FEI-2 and FEI-13 reverse the ranking and indicate significantly higher urban than rural poverty. The lack of robustness of FEI to the choice of the number of subgroups is striking.

Policy discussions and regional comparisons in Mozambique often focus on disparities and asymmetries among the southern, central, and northern 
TABLE 8

Regional Poverty Estimates under Different Poverty Lines

\begin{tabular}{|c|c|c|c|c|c|c|}
\hline Region & FEI-1 & FEI-2 & FEI-13 & $\mathrm{CBN}-1$ & $\mathrm{CBN}-2$ & $\mathrm{CBN}-13$ \\
\hline \multicolumn{7}{|c|}{ Head count $\left(P_{0}\right)$ : } \\
\hline & .728 & .685 & .497 & .835 & .809 & .663 \\
\hline North & $(.019)$ & $(.021)$ & $(.025)$ & $(.013)$ & $(.015)$ & $(.023)$ \\
\hline \multirow{2}{*}{ Central } & .644 & .604 & .633 & .822 & .810 & .738 \\
\hline & $(.019)$ & $(.020)$ & $(.020)$ & $(.015)$ & $(.015)$ & $(.016)$ \\
\hline \multirow[t]{3}{*}{ South } & .417 & .409 & .640 & .850 & .858 & .717 \\
\hline & $(.030)$ & $(.025)$ & $(.023)$ & $(.022)$ & $(.017)$ & $(.024)$ \\
\hline & .107 & .393 & .622 & .645 & .529 & .478 \\
\hline Maputo & $(.018)$ & $(.043)$ & $(.038)$ & $(.033)$ & $(.043)$ & $(.041)$ \\
\hline \multicolumn{7}{|c|}{ Poverty gap $\left(P_{1}\right)$ : } \\
\hline \multirow{2}{*}{ North } & .310 & .297 & .175 & .413 & .392 & .266 \\
\hline & $(.014)$ & $(.017)$ & $(.013)$ & $(.014)$ & $(.015)$ & $(.015)$ \\
\hline \multirow[t]{2}{*}{ Central } & .261 & .233 & .246 & .403 & .390 & .327 \\
\hline & $(.012)$ & $(.011)$ & $(.011)$ & $(.011)$ & $(.011)$ & $(.012)$ \\
\hline \multirow[t]{2}{*}{ South } & .134 & .124 & .248 & .472 & .479 & .302 \\
\hline & $(.012)$ & $(.011)$ & $(.015)$ & $(.020)$ & $(.019)$ & $(.016)$ \\
\hline \multirow[t]{2}{*}{ Maputo } & .030 & .124 & .240 & .256 & .187 & .165 \\
\hline & $(.008)$ & $(.017)$ & $(.023)$ & $(.024)$ & $(.021)$ & $(.020)$ \\
\hline \multicolumn{7}{|c|}{$\begin{array}{l}\text { Squared poverty } \\
\text { gap }\left(P_{2}\right):\end{array}$} \\
\hline \multirow[t]{2}{*}{ North } & .166 & .166 & .083 & .243 & .228 & .139 \\
\hline & $(.011)$ & $(.013)$ & (.009) & $(.012)$ & $(.012)$ & $(.011)$ \\
\hline \multirow[t]{2}{*}{ Central } & .137 & .118 & .126 & .239 & .228 & .180 \\
\hline & $(.008)$ & $(.008)$ & $(.008)$ & (.009) & $(.009)$ & $(.009)$ \\
\hline \multirow[t]{3}{*}{ South } & .058 & .053 & .124 & .298 & .305 & .159 \\
\hline & $(.007)$ & $(.006)$ & $(.010)$ & $(.016)$ & $(.016)$ & $(.011)$ \\
\hline & .014 & .056 & .121 & .132 & .090 & .077 \\
\hline Maputo & $(.006)$ & $(.010)$ & $(.015)$ & $(.016)$ & $(.013)$ & $(.012)$ \\
\hline
\end{tabular}

NotE. - Standard errors are in parentheses, adjusted for stratified cluster sample design.

regions of the country. In table 8 , we show poverty estimates for these three regions and Maputo City using the six different analytical approaches. Remarkable differences in the regional rankings emerge. FEI-1 and FEI-2 show poverty to be clearly falling by all three measures as one moves from north to south, whereas FEI-13 shows the exact opposite pattern. In Maputo City, FEI-13 finds poverty to be above average, while FEI-1 indicates that the Maputo head count is only one-sixth of the national head count, with similar results for the depth and severity of poverty. Broadly speaking, all the CBN results agree that poverty is more or less uniformly high outside the capital city and agree that poverty in Maputo is substantially lower than the rest of the country. The CBN-1 and CBN-2 poverty lines indicate that there is no statistically significant difference between the north and the center for any of the three poverty measures, while the south (excluding Maputo City) is significantly poorer according to all three measures. In contrast, $\mathrm{CBN}-13$ indicates no significant differences between the south and either of the other two regions but shows the center to be significantly poorer than the north on all three measures. 
Thus, geographic guidelines for targeting poverty alleviation are not robust to method. ${ }^{42}$ This is particularly true for all of the FEI lines. Within the CBN family of poverty lines, the results are considerably more robust, albeit with some reranking of regions depending on the number of basic needs food bundles considered. In addition, the changes in ordinal rankings that occur under the CBN lines should be kept in perspective. For example, although the CBN-13 head count index is significantly higher in the center than in the north, the difference between $74 \%$ and $66 \%$ may not matter much in practice, since poverty is extremely high throughout the country. No doubt, the how of poverty alleviation is sometimes more important than the where to policy makers. However, these results demonstrate the intricacies involved in pursuing regional targeting.

\section{Comparison with Other Welfare Indicators}

Given the wide dispersion in geographical poverty rankings, analysts and policy makers would be hard pressed to suggest methodologically robust allocation criteria. We, therefore, complemented our analysis of regional poverty estimates with nonmonetary welfare indicators. Table 9 shows the Pearson correlation coefficients between the provincial head counts from each of the poverty lines and provincially disaggregated nonconsumption-based indicators of welfare. ${ }^{43}$ Nonmonetary indicators available at the provincial level include infant and child mortality rates, life expectancy at birth, illiteracy rates, potable water access, stunting prevalence for children under 5 years of age, the human development index (HDI) of the United Nations Development Programme (UNDP), and the human poverty index (HPI). We do not see these indicators as superior welfare measures, and they should not supersede poverty analysis. Many of the nonmonetary welfare indicators reflect the consequences of past deprivation, whereas we are concerned here with current consumption. However, taken together, an interesting comparative reference point emerges.

In particular, there is a striking degree of consistency in the way correlations between poverty measures and the nonconsumption-based indicators are able to order the results of the different poverty line methodologies. FEI13 stands out with signs that are opposite to our expectations for most of the 15 measures considered. However, all of the other pair-wise correlations show the expected signs. The highest correlations occur under FEI-1, most of which are statistically significant at the 5\% level. FEI-2, CBN-1, and CBN-2 show very substantial correlation with the nonmonetary welfare indicators, but only a few of these are statistically significant. Correlations of the CBN-13 measures are somewhat lower, and none of them is significant at the 5\% level.

Although useful, correlations of provincial-level data on poverty head count, literacy rates, infant mortality rates, and so forth obscure the underlying distributions. It is, therefore, possibly more instructive to analyze how the different poverty estimates are correlated with key health outcomes at the level of individual children. Table 10 presents the Pearson correlation coefficients for the three main $P_{\alpha}$ poverty measures and anthropometric $Z$-scores for children 
TABLE 9

Pearson Correlation Coefficients of Provincial-Level Poverty Head Count Index and Nonconsumption-Based Measures of Well-Being

\begin{tabular}{|c|c|c|c|c|c|c|}
\hline \multirow[b]{2}{*}{ COEFFICIENT } & \multicolumn{6}{|c|}{ Poverty Line Method } \\
\hline & FEI-1 & FEI-2 & FEI-13 & $\mathrm{CBN}-1$ & $\mathrm{CBN}-2$ & CBN-13 \\
\hline $\begin{array}{r}\text { Child mortality } \\
\text { rate (census) }\end{array}$ & $.69^{*}$ & .40 & -.38 & .40 & .42 & .13 \\
\hline $\begin{array}{l}\text { Child mortality } \\
\text { rate (DHS) }\end{array}$ & $.60^{*}$ & $.62 *$ & .00 & .21 & .18 & .34 \\
\hline Stunting (IAF) & .32 & .04 & -.16 & .19 & .25 & .12 \\
\hline $\begin{array}{l}\text { Female illiteracy } \\
\text { (census) }\end{array}$ & $.84 *$ & .55 & -.27 & .49 & .53 & .35 \\
\hline $\begin{array}{l}\text { Female illiteracy } \\
\text { (IAF) }\end{array}$ & $.81^{*}$ & .52 & -.24 & .49 & .58 & .39 \\
\hline $\begin{array}{l}\text { Male illiteracy } \\
\text { (census) }\end{array}$ & $.76^{*}$ & .48 & -.44 & 42 & .43 & .17 \\
\hline $\begin{array}{l}\text { Male illiteracy } \\
\text { (IAF) }\end{array}$ & $.78^{*}$ & .48 & -.31 & .51 & .55 & .32 \\
\hline $\begin{array}{l}\text { Total illiteracy } \\
\text { (census) }\end{array}$ & $.80^{*}$ & .50 & -.34 & .48 & .51 & .29 \\
\hline $\begin{array}{l}\text { Infant mortality } \\
\text { rate (census) }\end{array}$ & $.68^{*}$ & .40 & -.35 & .41 & .43 & .14 \\
\hline $\begin{array}{l}\text { Life expectancy } \\
\quad \text { (census) }\end{array}$ & $-.71 *$ & -.39 & .31 & -.44 & -.50 & -.25 \\
\hline $\begin{array}{l}\text { Infant mortality } \\
\text { rate (DHS) }\end{array}$ & $.84 *$ & $.76^{*}$ & .10 & $.66^{*}$ & $.63^{*}$ & .54 \\
\hline $\begin{array}{l}\text { Potable water } \\
\text { (census) }\end{array}$ & $.72 *$ & .38 & -.18 & .53 & .59 & .42 \\
\hline $\begin{array}{l}\text { Potable water } \\
\text { (IAF) }\end{array}$ & $.66^{*}$ & .34 & .01 & .55 & $.67 *$ & .53 \\
\hline HDI (1998) & $-.73^{*}$ & -.39 & .30 & -.57 & $-.62 *$ & -.29 \\
\hline HPI (1997) & $.77 *$ & .47 & -.37 & .41 & .43 & .24 \\
\hline
\end{tabular}

NoTE. - DHS = demographic and health survey; IAF = "Inquérito nacional aos agregados familiares sobre as condições de vida"; HDI = human development index; HPI = human poverty index.

* Significant at the $5 \%$ level.

TABLE 10

Correlation Coefficients of Individual Level Child ANThropometric Z-SCORES With HOUSEHOLD-LeVEL POVERTy Measures

\begin{tabular}{lccc}
\hline & \multicolumn{3}{c}{ Height-For-Age Z-Score } \\
\cline { 2 - 4 } CoEfFICENT & $P_{0}$ & $P_{1}$ & $P_{2}$ \\
\hline FEI-1 & $-.045^{*}$ & $-.049^{*}$ & $-.034^{*}$ \\
FEI-2 & -.007 & .006 & .017 \\
FEI-13 & .003 & .012 & .013 \\
CBN-1 & $-.086^{*}$ & -.026 & -.011 \\
CBN-2 & $-.079^{*}$ & -.022 & -.006 \\
CBN-13 & -.002 & -.009 & -.008 \\
\hline
\end{tabular}

* Significant at the $5 \%$ level. 
less than 5 years of age in the IAF sample. The table shows results for heightfor-age, a measure of long-term nutritional status. Both FEI-2 and FEI-13 have unexpected positive correlations between poverty and the height-for-age $Z$-score. On the other hand, FEI-1, CBN-1, and CBN-2 have sizeable correlations with height-for-age $Z$-score, with the direction of the correlation as expected. CBN13 has close to zero correlation with height-for-age Z-scores.

The high FEI-1 correlations with nonmonetary indicators are striking. It might, therefore, be tempting to discard FEI-2 and FEI-13 on the above basis. However, it is well documented in Mozambique that food is more expensive in urban than in rural areas. Moreover, the FEI-1 correlation with nonmonetary indicators may, in large part, be explained by remoteness. Under FEI-1, the poorest provinces are in the north and in the center. Many of these areas are agriculturally productive but are not served well by infrastructure. Hence, food prices tend to be lower than in the south because of the relatively large extent of home consumption in the north. The southern provinces, therefore, have relatively higher poverty lines and poverty incidence under the CBN approach, which is sensitive to these price differentials. Yet many social services are more developed in the south, which manifests in relatively better performance on health and education indicators. Therefore, the common factor of remoteness, resulting in poor social services and low food prices in the food-exporting north, can help explain the strong correlations under FEI-1.

\section{Characteristics of the Poor}

Apart from the regional incidence and severity of poverty, policy makers are typically interested in the characteristics of poor households, which, taken together, are often referred to as a poverty profile. This provides clues as to the determinants of poverty and is useful in the design of poverty alleviation policies and programs based on household targeting, as opposed to regional targeting.

We investigated how a number of key characteristics and variables vary between the poor and the nonpoor for each of the six methods. The tables are not included here because of space constraints. ${ }^{44}$ The analysis showed that the characteristics of the poor depend only to a very limited extent on the method used for setting the poverty line. Thus, larger households are more likely to be poor regardless of the poverty line, even after controlling for economies of household size. Female-headed households are, on average, more likely to be poor than male-headed households in urban areas, and less likely to be poor than male-headed households in rural areas, again regardless of the method. Poor families have higher dependency ratios and own less land under all six sets of poverty lines. Measures of human capital display a large gap between urban and rural sectors and a smaller gap between the poor and the nonpoor. That is, literacy rates, the likelihood of past school attendance, and children's current school enrollment are higher among the urban and the nonpoor than among the rural and poor. Although estimates of the size of the poor and nonpoor gaps vary, these tendencies hold for each of the lines. For 
TABLE 11

Spearman Rank Correlation Coefficients between Provincial Head Counts

\begin{tabular}{lllllll}
\hline Coefficient & FEI-1 & FEI-2 & FEI-13 & CBN-1 & CBN-2 & CBN-13 \\
\hline FEI-1 & & & & & & \\
FEI-2 & $.910^{*}$ & & & & & \\
FEI-13 & .100 & .336 & & & & \\
CBN-1 & .482 & .464 & .409 & & & \\
CBN-2 & .373 & .327 & .409 & $.964^{*}$ & & \\
CBN-13 & $.646^{*}$ & $.709 *$ & .664 & $.782^{*}$ & $.782^{*}$ & \\
\hline
\end{tabular}

* Test of different rank correlations can be rejected at the 5\% level of significance.

health variables, it was found that poor and rural children are less likely to receive a full set of vaccinations and more likely to be stunted (low height for age). The incidence of low birth weight is not highly correlated with poverty status according to most of the poverty lines.

In sum, poverty profile comparisons of household characteristics appear to be much more robust to choice of poverty line approach than geographical poverty comparisons. The poor, on average, have larger families, higher dependency ratios, less land, less education, worse health, and often benefit less from public services. This is an important finding, because it implies that all approaches would point to the same proxy means indicators for poverty, and, hence, that targeting on household characteristics is much more robust than regional targeting.

\section{Assessing the Evidence}

The FEI approach does not perform well in the comparisons undertaken in this article. In contrast, none of the CBN versions applied here generated results that could be dismissed on a priori grounds. Yet this immediately leads to more questions. First, which version of CBN should be used-fixed or multiple bundles? Second, if one decides in favor of multiple bundles, what is the optimal number of subgroups over which the food bundles should be allowed to vary? Third, and more fundamentally, how robust is a poverty profile based on CBN to choices regarding subgroups?

Starting with the last question, Section VI showed that conclusions regarding characteristics of the poor are robust to choice of method. How robust are provincial poverty profiles? Table 11 shows the Spearman rank correlations between provincial head counts. An asterisk indicates that the hypothesis of different rank is rejected at the $5 \%$ level of significance. The CBN provincial ranks are highly correlated with each other, and for all of them the hypothesis of different ranks is rejected. We conclude that, for these data, CBN poverty profiles are relatively robust to choice of subgroups. It also appears from the table that the FEI profiles are not robust- the provincial ranks under FEI-13 are significantly different from the other FEI results. The rank correlations between the FEI and the CBN results are all positive but not very large, and 
only two (CBN-1 with FEI-1 and FEI-2) of nine rank correlations are significant, that is, we cannot reject the null hypothesis that the rankings are different.

To assess the optimal number of subgroups under CBN, one needs to consider carefully the food bundles used in the $\mathrm{CBN}-1, \mathrm{CBN}-2$, and $\mathrm{CBN}-$ 13 poverty lines. Most important, it should be verified that the CBN multiple bundles represent comparable standards of living and that the food bundles underlying the CBN-2 and CBN-13 poverty lines are not affected by differences in real income. Tables 12 and 13 show the composition of the food bundles in the food poverty lines. Although in all cases the majority of calories are derived from the basic staples-maize, cassava, and rice- there are substantial movements in the composition of the bundles. Large substitution is especially observed between maize and cassava. Yet it does not seem to be the case that any one of the bundles dominates in that most Mozambicans would agree it is superior. One can, for example, compare the rural and the urban $\mathrm{CBN}-2$ bundles. Maize and cassava dominate in the rural diet, while the urban bundle also has substantial rice, bread, and sugar; this pattern is even more pronounced in the southern urban bundles in CBN-13. The urban bundle does appear somewhat more diversified. Yet the rural bundle actually has a little more of such superior foods as fish, meat, and groundnuts.

To what extent are movements in food bundle composition caused by regionally varying relative prices? Most CBN analyses do not address the question of substitution and relative price differences, the notable exceptions being those authored by Peter Lanjouw, Martin Ravallion, and Binayak Sen. ${ }^{45}$ In tables 14 and 15, the changes taking place between CBN-13 and CBN-1 in the rural and urban food poverty lines, respectively, are decomposed and shown separately for each region. The tables are confined to the most important products and show how quantity and price changes result in increases and decreases in outlays on each product in the $\mathrm{CBN}-13$ food poverty lines (relative to CBN-1). The net effect of each product's implied change in outlay is its contribution to the difference between the $\mathrm{CBN}-1$ and the $\mathrm{CBN}-13$ food poverty line. There are more negative changes in outlay (i.e., lower outlay in regional than in national bundle) because the food poverty lines tend to be lower under $\mathrm{CBN}-13$.

Many instances of substitution are evident among the basic staples (maize, maize flour, cassava, and cassava flour) in response to local variations in the price per calorie of these foods. In almost all cases, CBN-13 is associated with a significant shift to a cheaper source of calories, such as maize to cassava in rural and urban Nampula, or cassava to maize in urban Niassa/Cabo Delgado, urban Zambézia/Sofala, and rural Maputo Province. This is according to expectations, and it illustrates the advantage of the multiple-bundle CBN approach in terms of capturing locally relevant demand behavior, that is, specificity. Yet we observe universally higher sugar consumption in urban areas and mostly higher consumption of cooking oil and more bread in the southern cities, despite the fact that these foods do not provide cheap calories. 
TABLE 12

Calorie Shares by Subgroups (Rural; \%)

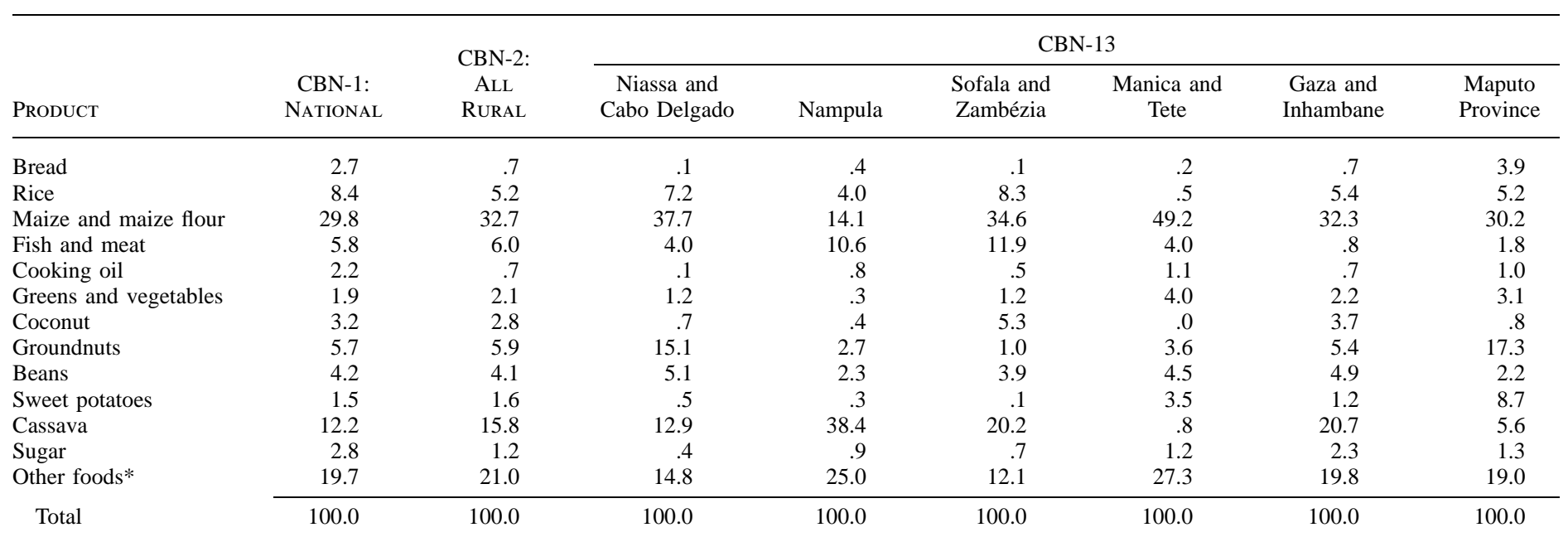

* Other foods comprises more than 100 different categories not included in the CBN-1 and CBN-2 bundles. 
TABLE 13

Calorie Shares by Subgroup (Urban; \%)

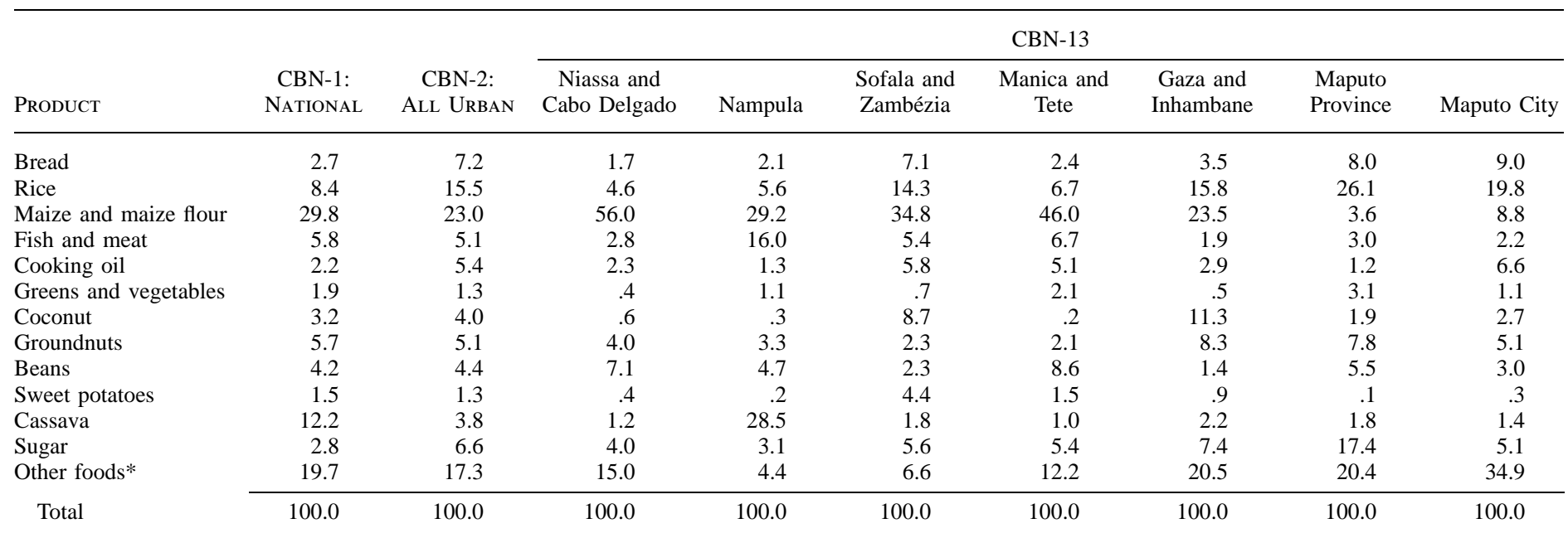

* Other foods comprises more than 100 different categories not included in the CBN-1 and CBN-2 bundles. 
TABLE 14

Decomposition of the Change in RuRal Food Poverty Lines

\begin{tabular}{|c|c|c|c|c|c|c|c|c|c|c|}
\hline Domain & Unit & Bread & Rice & Maize & Maize Flour & Dried Fish & Cooking Oil & Cassava & Cassava Flour & Sugar \\
\hline \multicolumn{11}{|l|}{$\begin{array}{l}\text { CBN-1 fixed national } \\
\text { bundle: }\end{array}$} \\
\hline Calories in bundle & kcal & 58 & 180 & 172 & 464 & 84 & 46 & 131 & 131 & 61 \\
\hline CBN-13: & & & & & & & & & & \\
\hline \multicolumn{11}{|l|}{$\begin{array}{c}\text { Niassa and Cabo } \\
\text { Delgado: }\end{array}$} \\
\hline Calories in bundle & kcal & 3 & 156 & 65 & 742 & 55 & 2 & 59 & 220 & 9 \\
\hline Cost per calorie & MT/kcal & 5.76 & 1.52 & 1.51 & .85 & 1.96 & 3.58 & 1.39 & 1.62 & 2.72 \\
\hline Implied change in & MT & & & -162 & 237 & & -150 & -100 & 144 & -140 \\
\hline \multicolumn{11}{|l|}{ Nampula: } \\
\hline Calories in bundle & kcal & 9 & 86 & 17 & 288 & 193 & 18 & 95 & 736 & 19 \\
\hline Cost per calorie & MT/kcal & 4.60 & 2.13 & .96 & .94 & 1.43 & 1.82 & 1.29 & .64 & 1.98 \\
\hline $\begin{array}{l}\text { Implied change in } \\
\text { outlay }\end{array}$ & MT & -226 & -201 & -149 & -166 & 156 & -52 & -46 & 387 & -83 \\
\hline \multicolumn{11}{|l|}{ Sofala and Zambezia: } \\
\hline Calories in bundle & kcal & 3 & 181 & 33 & 711 & 219 & 11 & 85 & 354 & 15 \\
\hline \multirow{2}{*}{$\begin{array}{l}\text { Cost per calorie } \\
\text { Implied change in } \\
\text { outlay }\end{array}$} & $\mathrm{MT} / \mathrm{kcal}$ & 3.29 & 1.43 & .97 & .88 & 1.18 & 3.12 & 1.16 & 1.20 & 2.11 \\
\hline & MT & -183 & 2 & -134 & 218 & 160 & -111 & -53 & 267 & -97 \\
\hline
\end{tabular}




\begin{tabular}{|c|c|c|c|c|c|c|c|c|c|c|}
\hline \multicolumn{11}{|l|}{ Manica and Tete: } \\
\hline Calories in bundle & kcal & 5 & 10 & 529 & 503 & 44 & 22 & 15 & 1 & 25 \\
\hline $\begin{array}{l}\text { Cost per calorie } \\
\text { Imnlied change in }\end{array}$ & MT/kcal & 3.45 & 2.65 & .65 & .96 & 2.95 & 3.66 & 1.66 & .78 & 2.54 \\
\hline $\begin{array}{l}\text { Implied change in } \\
\text { outlay } \\
\text { Gaza and Inham- } \\
\text { bane: }\end{array}$ & MT & -185 & -449 & 233 & 37 & -118 & -89 & -192 & -101 & -89 \\
\hline Calories in bundle & kcal & 15 & 115 & 326 & 366 & 1 & 14 & 432 & 10 & 49 \\
\hline $\begin{array}{l}\text { Cost per calorie } \\
\text { Implied change in }\end{array}$ & MT/kcal & 8.98 & 2.02 & .92 & 1.81 & 3.00 & 2.59 & 1.41 & 9.45 & 2.17 \\
\hline $\begin{array}{l}\text { outlay } \\
\text { Maputo Province: }\end{array}$ & MT & -391 & -131 & 141 & -177 & -250 & -83 & 425 & $-1,144$ & -26 \\
\hline Calories in bundle & kcal & 83 & 110 & 466 & 174 & 2 & 21 & 110 & 8 & 27 \\
\hline $\begin{array}{l}\text { Cost per calorie } \\
\text { Implied change in }\end{array}$ & MT/kcal & 3.59 & 1.95 & 1.10 & 1.48 & 8.93 & 3.36 & 3.79 & 3.05 & 2.20 \\
\hline outlay & MT & 88 & -136 & 324 & -430 & -733 & -85 & -78 & -377 & -73 \\
\hline
\end{tabular}

Note - Kcal $=$ kilocalorie; MT $=$ Mozambican meticais. 
TABLE 15

Decomposition of the Change in Urban Food Poverty Lines

\begin{tabular}{|c|c|c|c|c|c|c|c|c|c|c|}
\hline Domain & Unit & Bread & Rice & Maize & Maize Flour & Dried Fish & Cooking Oil & Cassava & Cassava Flour & Sugar \\
\hline \multicolumn{11}{|l|}{$\begin{array}{l}\text { CBN-1 fixed national } \\
\text { bundle: }\end{array}$} \\
\hline Calories in bundle & kcal & 58 & 180 & 172 & 464 & 84 & 46 & 131 & 131 & 61 \\
\hline \multicolumn{11}{|l|}{$\begin{array}{l}\text { Niassa and Cabo Del- } \\
\text { gado: }\end{array}$} \\
\hline Calories in bundle & kcal & 36 & 98 & 104 & 1,084 & 38 & 48 & 20 & 6 & 84 \\
\hline Cost per calorie & $\mathrm{MT} / \mathrm{kcal}$ & 5.76 & 1.87 & 1.65 & .70 & 4.39 & 2.76 & 2.88 & .91 & 1.89 \\
\hline $\begin{array}{l}\text { Implied change in } \\
\text { outlay } \\
\text { Nampula: }\end{array}$ & MT & -126 & -152 & -113 & 433 & -200 & 5 & -320 & -114 & 45 \\
\hline Calories in bundle & $\mathrm{kcal}$ & 45 & 121 & 64 & 554 & 280 & 27 & 316 & 294 & 67 \\
\hline $\begin{array}{l}\text { Cost per calorie } \\
\text { Imnlied change in }\end{array}$ & MT/kcal & 3.89 & 1.47 & 1.58 & 1.17 & .97 & 1.82 & 1.05 & .95 & 1.59 \\
\hline $\begin{array}{l}\text { outlay } \\
\text { Sofala and Zambezia: }\end{array}$ & MT & -51 & -88 & -170 & 105 & 190 & -36 & 195 & 156 & 10 \\
\hline Calories in bundle & kcal & 155 & 311 & 102 & 653 & 66 & 127 & 25 & 14 & 122 \\
\hline Cost per calorie & MT/kcal & 2.50 & 1.62 & 1.85 & .99 & 1.71 & 2.67 & 1.21 & 2.17 & 1.75 \\
\hline $\begin{array}{l}\text { Implied change in } \\
\text { outlay }\end{array}$ & MT & 242 & 212 & -130 & 188 & -29 & 215 & -129 & -256 & 107 \\
\hline
\end{tabular}




\begin{tabular}{|c|c|c|c|c|c|c|c|c|c|c|}
\hline \multicolumn{11}{|l|}{ Manica and Tete: } \\
\hline Calories in bundle & kcal & 53 & 145 & 184 & 784 & 112 & 111 & 21 & 1 & 116 \\
\hline Cost per calorie & MT/kcal & 5.05 & 2.02 & 1.23 & 1.03 & 2.34 & 2.90 & 1.39 & 1.13 & 1.86 \\
\hline $\begin{array}{l}\text { Implied change in } \\
\text { outlay }\end{array}$ & MT & -28 & -71 & 15 & 329 & 67 & 188 & -153 & -147 & 104 \\
\hline Gaza and Inhambane: & & & & & & & & & & \\
\hline Calories in bundle & kcal & 75 & 342 & 161 & 349 & 5 & 63 & 23 & 24 & 161 \\
\hline Cost per calorie & MT/kcal & 12.90 & 1.44 & .90 & 1.09 & 3.00 & 2.11 & 3.74 & 4.04 & 1.65 \\
\hline $\begin{array}{l}\text { Implied change in } \\
\text { outlay }\end{array}$ & MT & 221 & 234 & -10 & -125 & -238 & 35 & -402 & -432 & 165 \\
\hline Maputo Province: & & & & & & & & & & \\
\hline Calories in bundle & kcal & 174 & 566 & 7 & 71 & 11 & 26 & 29 & 10 & 377 \\
\hline Cost per calorie & MT/kcal & 6.64 & 1.32 & 1.78 & 2.18 & .98 & 7.32 & 2.86 & 2.80 & 1.82 \\
\hline Implied change in & MT & 770 & 500 & -203 & -856 & -71 & -152 & -200 & -340 & 576 \\
\hline Maputo City: & M11 & $1 / 10$ & 309 & 290 & -856 & $-/ 1$ & -152 & -290 & -340 & 310 \\
\hline Calories in bundle & kcal & 199 & 439 & 89 & 106 & 7 & 146 & 29 & 3 & 113 \\
\hline Cost per calorie & MT/kcal & 4.10 & 1.43 & 1.09 & 1.68 & 2.27 & 2.12 & 2.38 & 2.23 & 2.11 \\
\hline $\begin{array}{l}\text { Implied change in } \\
\text { outlay }\end{array}$ & MT & 577 & 370 & -90 & -602 & -175 & 211 & -242 & -286 & 110 \\
\hline
\end{tabular}

NoTE. - Kcal $=$ kilocalorie MT $=$ Mozambican meticais. 
Does this mean that urban bundles are superior? It might, but observed unit costs per calorie do not fully reflect household-specific shadow costs.

The preparation of maize and cassava requires much more time and fuel than other foods. Rural and urban differences in fuel costs and in commuting time between house and place of work may help account for some of that variation. Food eaten away from home is more common among urban occupations and would, by necessity, include more bread ${ }^{46}$ Also, cassava has high marketing costs and is not a cheap food in the towns. No systematic pattern in meat and fish consumption between rural and urban areas is observed. In sum, substitution effects in response to relative price differences are important, pointing to a need for regionalized bundles. Careful inspection of the food bundles cannot reveal any clear-cut case for which the CBN regionspecific food bundles are contaminated by income effects. We conclude that the region-specific CBN approach appears to have the advantage of specificity without suffering from the drawback of inconsistent comparisons.

\section{Conclusions}

Poverty lines can be set in different ways, and policy makers should be aware of how the underlying poverty measures have been constructed before using the derived poverty profiles to formulate poverty reduction policies. The two main methodologies for setting poverty lines, the FEI and CBN methods, are similar in that both are based on the cost of meeting caloric requirements and nonfood necessities in a given environment, using the observed consumption behavior of poor households given prevailing local prices. They differ in the relative weight given to specificity (applying locally pertinent notions of poverty) and consistency (treating persons with same living standards equally). The trade-off between specificity and consistency also emerges when choosing the specific variant of each methodology, namely, the number of poverty lines estimated under the FEI methodology and the number of distinct food consumption bundles permitted using the CBN methodology. As the number of bundles-implicit in FEI and explicit in $\mathrm{CBN}$ - increases, specificity increases, as does the risk of inconsistent poverty comparisons.

In this article, we have revisited this debate, estimating poverty lines and poverty measures by using three variants of the FEI and CBN methodologies and focusing on recent data from Mozambique. The analysis shows that, in the case of Mozambique, rural and urban and provincial-level rankings of poverty indexes are not robust to the choice of poverty line method. Some of this can be explained by the tendency of the FEI method to underestimate urban poverty under a single national poverty line (FEI-1) and to overestimate urban poverty under the FEI-2 method with separate poverty lines for rural and urban areas. In the Mozambique data, the FEI- 2 and FEI-13 poverty lines suggest the cost of living in urban areas is twice that in rural areas, which does appear too high. On the other hand, all three versions of the CBN method considered here yield plausible differences in cost of living and poverty rankings that are similar to each other. The food bundles and poverty lines derived 
from the multiple-bundles versions of the CBN poverty lines (CBN-2 and $\mathrm{CBN}-13$ ) are consistent with consumer substitution effects in a country where there is high regional variability in the relative prices of basic foods.

Unlike the rural and urban and provincial poverty rankings, the characteristics of the poor-that is, the individual-level as well as household-level correlates of poverty - are largely robust to all of the poverty line methods examined here. For most of the variables considered, the poverty line method matters little for conclusions regarding the characteristics of the poor along the lines of standard poverty profiles. This is because the household characteristics of the poor are only weakly related to the systematic regional price variations that drive the geographic differences in poverty lines across poverty line methodologies, at least in the Mozambique case.

While the present analysis provides support for the hypothesis that CBNbased poverty profiles are more robust than FEI-based profiles in Mozambique, we note that the results are also somewhat sensitive to the number of consumption bundles permitted. Furthermore, we specifically do not claim that these results constitute the "final word" on the relative merits of the FEI and CBN methods or of the variations within each approach. We have aimed at providing insights from a rigorous country case study, but our results cannot be generalized to all other settings.

The implication of these findings is that poverty-oriented policy interventions can, in principle, be targeted toward observable household characteristics related to poverty, such as household size, dependency ratio, education, and land, provided cost-effective targeting mechanisms are available. The robustness of geographical targeting based on regional poverty profiles is more questionable because of the sensitivity of the results to the choice of poverty line methodology. Finally, it is clear that poverty is a widespread and endemic feature in Mozambique affecting a broad range of socioeconomic and geographic groups. We would caution that consumption poverty does not capture the full multidimensional character of poverty, especially as it pertains to access to public services, and that it would not be wise to rely in any narrow sense on these estimates in making suggestions on the allocation of government budgets. Reducing poverty in Mozambique will require both broad-based economic growth and extended reach of public services to underserved groups.

Notes

* The authors' names are listed in reverse alphabetical order. We are grateful for useful and pertinent comments from two anonymous referees. AERC and Danida sponsorhip is also acknowledged, and we thank the National Institute of Statistics in Mozambique for access to household survey data, and the Ministry of Planning and Finance for general support in carrying out this research.

1. See, e.g., Martin Ravallion, Poverty Comparisons (Chur, Switzerland: Harwood Academic Publishers, 1994); Amartya Sen, Development as Freedom (New York: Knopf, 1999); Ravi Kanbur and Lyn Squire, "The Evolution of Thinking about Poverty: Exploring the Interactions," background paper for World Development Report 2000: 
Attacking Poverty (Washington, D.C.: World Bank, 1999); Deepa Narayan, Raj Patel, Kai Schafft, Anne Rademacher, and Sarah Koch-Schulte, Can Anvone Hear Us? (Washington, D.C.: World Bank, 2000).

2. See Martin Ravallion and Benu Bidani, "How Robust Is a Poverty Profile?" World Bank Economic Review 8, no. 1 (1994): 75-102; Martin Ravallion and Binayak Sen, "When Method Matters: Monitoring Poverty in Bangladesh," Economic Development and Cultural Change 44, no. 4 (1996): 761-92; and Quentin Wodon, "Food Energy Intake and Cost of Basic Needs: Measuring Poverty in Bangladesh," Journal of Development Studies 34, no. 2 (1997): 66-101.

3. Often a single FEI poverty line or a rural and urban pair of FEI poverty lines is compared with a set of CBN lines defined by a single food consumption bundle and multiple region-specific price vectors corresponding to that bundle. For example, Ravallion and Bidani and Wodon each use a pair of rural and urban FEI poverty lines but a much more disaggregated set of regional price vectors (50 and 14, respectively) to construct CBN poverty lines.

4. Michael Lipton and Martin Ravallion, "Poverty and Policy," in Handbook of Development Economics, vol. 3, ed. J. Behrman and T. N. Srinivasan (Amsterdam: Elsevier, 1995).

5. Benu Bidani and Martin Ravallion, "A Regional Poverty Profile for Indonesia," Bulletin of Indonesian Economic Studies 29, no. 3 (1993): 37-68. When poverty lines are based on a single consumption bundle, they function as a low-income Laspeyre price index. When multiple bundles are permitted in addition to price variation, poverty lines may be viewed more generally as a low-income "cost-of-living" index.

6. Martin Ravallion, "Poverty Lines in Theory and Practice," Living Standard Measurement Study Working Paper no. 133 (World Bank, Washington, D.C., 1998); and Angus Deaton, The Analvsis of Household Survevs: A Microeconometric Approach to Development Policy (Baltimore: Johns Hopkins University Press, 1997).

7. For example, if two deflators were sufficiently different, under one deflator, the $\mathrm{CDF}$ of one subgroup could dominate the CDF of another group over the entire range of observed welfare levels, whereas the opposite result could obtain under the other deflator. Yet either of these scenarios could be assessed as robust by conventional dominance tests because, given the real welfare distribution, any poverty line would yield the same welfare ranking of subgroups.

8. Other potential points of contention include the setting of caloric requirements, equivalence scales, poverty indexes, and the calorie content of various food items. We do not pursue the difficulties inherent in these steps here. They are well covered in the literature. See A. B. Atkinson, "Comparing Poverty Rates Internationally: Lessons from Recent Studies in Developing Countries," World Bank Economic Review 5, no. 1 (1991): 3-21; and Lipton and Ravallion.

9. V. M. Dandekar and N. Roth, Poverty in India (Pune: Indian School of Political Economy, 1971).

10. Joel Greer and Erik Thorbecke, "Food Poverty Profile Applied to Kenyan Smallholders," Economic Development and Cultural Change 35, no. 1 (1985): 115-41, and "A Methodology for Measuring Food Poverty Applied to Kenya," Journal of Development Economics 24 (1986): 59-74.

11. Ravallion and Bidani.

12. Ravallion and Sen (n. 2 above); Wodon (n. 2 above).

13. Ravallion, "Poverty Lines in Theory and Practice."

14. Ravallion and Bidani (n. 2 above).

15. Greer and Thorbecke, "Food Poverty Profile."

16. It is also noteworthy that both poverty lines are well above the cost of acquiring the region-specific bundles, since the $\mathrm{CBN}-1$ bundle is not the cost-minimizing allocation for achieving that level of utility in either region. This aspect alone will not generate inconsistent poverty comparisons between region $\mathrm{A}$ and region $\mathrm{B}$, but it may 
affect intraregional poverty comparisons if welfare dominance between subgroups does not obtain within this range (i.e., if poverty comparisons are not robust to the specific placement of the poverty line).

17. Ravallion and Bidani.

18. Ibid., p. 76. For this reason, poverty lines also tend to increase with mean income even if they are supposed to reflect absolute, not relative, poverty (Martin Ravallion, Gaurav Datt, and Dominique van de Walle, "Quantifying Absolute Poverty in the Developing World," Review of Income and Wealth 37 [1991]: 345-61).

19. Ravallion and Bidani; Wodon; and World Bank, "Madagascar Poverty Assessment," Report no. 14044-MAG (World Bank, Washington, D.C., 1996).

20. Ravallion and Sen.

21. Ravallion and Bidani and Wodon.

22. Peter Lanjouw, "Regional Poverty in Pakistan: How Robust Are Conclusions?" (World Bank, Washington, D.C., 1994, photocopied); Gaurav Datt, Dean Jolliffe, and Manohar Sharma, "A Profile of Poverty in Egypt: 1997," FCND Discussion Paper no. 49 (International Food Policy Research Institute, Washington, D.C., 1998); Ministry of Planning and Finance, Eduardo Mondlane University, International Food Policy Research Institute, "Understanding Poverty and Well-Being in Mozambique: The First National Assessment (1996-1997)" (report, Ministry of Planning and Finance, Maputo, 1998).

23. As in other surveys, food quantity information (e.g., grams of particular foods consumed) is measured with more error than the monetary value of this consumption. The primary reason for this is the reporting of consumption in nonstandard units, such as bowls, heaps, etc. To minimize the effects of this measurement error, households with extreme values for quantities are excluded from the FEI regressions and the construction of the CBN food bundles. As the monetary value data are more reliable, these households are included in the analysis following the specification of poverty lines.

24. Deaton (n. 6 above); Steven Howes and Jean Olson Lanjouw, "Poverty Comparisons and Household Survey Design." Living Standards Measurement Study Working Paper no. 129 (World Bank, Washington, D.C., 1997). Also see StataCorp, Stata Statistical Software: Release 7.0 (College Station, Tex.: Stata Corporation, 2000).

25. See Finn Tarp and Channing Arndt, eds., "Facing the Development Challenge in Mozambique: An Economy-Wide Perspective," MERISSA Research Report (International Food Policy Research Institute, Washington, D.C., 2000), for this and other descriptive data used in the remainder of this section.

26. Instituto Nacional de Estatística, "Recenseamento geral da população e habitação: Resultados definitivos" (General population and housing census: Final results) (report, National Institute of Statistics, Maputo, 1999).

27. Channing Arndt and Finn Tarp, "Agricultural Technology, Risk, and Gender: A CGE Analysis of Mozambique,” World Development 28 (2000): 1307-26.

28. Government of the Republic of Mozambique, "Interim Poverty Reduction Strategy Paper" (Maputo, 2000, photocopied).

29. Jesko Hentschel and Peter Lanjouw, "Constructing an Indicator of Consumption for the Analysis of Poverty: Principles and Illustrations with Reference to Ecuador," Living Standard Measurement Studv Working Paper no. 124 (World Bank, Washington, D.C., 1996).

30. Ministry of Agriculture and Fisheries (MAP), "Sistema de informação do mercado agrícola" (Agricultural market information system) (Maputo, 1998, photocopied).

31. Walter Cavero, "Inquérito nacional aos agregados familiares sobre condições de vida: Relatório de missão" (National household survey of living conditions: Mission report) (unpublished manuscript, National Institute of Statistics, Maputo, 1998).

32. World Health Organization (WHO), "Energy and Protein Requirements," Technical Report Series no. 724 (WHO, Geneva, 1985). 
33. The regression was run once on the entire sample to establish the FEI-1 poverty line and run separately on the urban and rural subsamples to establish FEI-2 lines. Separate regressions were run on each of the 13 regions to give the FEI-13 lines.

34. See Greer and Thorbecke, "Food Poverty Profile" (n. 10 above).

35. Observations are excluded if $\mid$ DFBETA $_{i} \mid>2 / n^{0.5}$. This is a common criterion for excluding outliers, as described in D. A. Belsley, E. Kuh, and R. E. Welsch, Regression Diagnostics (New York: Wiley, 1980).

36. Peter Lanjouw and Martin Ravallion ("Poverty and Household Size," Economic Journal 105 [1995]: 1415-34) have explored the implications of different equivalence scales. While it appears that equivalence scales may matter in cross-country comparisons of poverty (G. R. Lancaster and M. R. Valenzuela, "A Cross-Country Study of Household Poverty and Inequality on Unit Record Household Budget Data," Economic Development and Cultural Change 48, no. 1 [1999], 177-208), there is no reason to believe this to be the case in our comparison of methods for a given country.

37. See Ravallion, "Poverty Lines in Theory and Practice" (n. 6 above). We initially used this approach on the Mozambique data, but the range of the resulting CBN-13 poverty lines appeared implausibly large. The large differences in poverty lines could not be explained entirely by differing prices, and examination of the consumption bundles suggested that the poverty lines in southern Mozambique commanded a higher standard of living than the poverty lines in northern regions. We therefore opted for using the consumption bundle of people whose food energy intake is below the requirement and scaled up to requirements. On reexamination, we can affirm that the comparisons in this article would not change in any important way had the more conventional approach been employed.

38. Ibid. Please also note that $\mathrm{CBN}-1$ without allowing for regional price variation would resemble FEI-1, although they would not be identical.

39. The use of unit values instead of market prices implies that we are not controlling for differences in quality of the foods consumed. We do not explore the potential biases from such quality differences in this article.

40. Ravallion, "Poverty Lines in Theory and Practice."

41. James Foster, Joel Greer, and Erik Thorbecke, "A Class of Decomposable Poverty Measures," Econometrica 52 (1984): 761-66.

42. The same holds true when analysis is carried out at the provincial level, where several statistically significant rerankings occur.

43. Because of the nature of the data, these comparisons are made using aggregated data for the 10 provinces of Mozambique plus the city of Maputo, comparing provincial-level measures. As the sample size is only 11, statistical significance is not achieved easily.

44. The poverty profile tables are available in a research report to the African Economic Research Consortium (AERC): G. Dava et al., "Mozambique Country Study," Research Report to the Poverty, Income Distribution, and Labor Market Issues project (AERC, Nairobi, 2000).

45. Lanjouw (n. 22 above); and Ravallion and Sen (n. 2 above).

46. Geral Abílio Bazo has shown that bread is an important source of calories even among the extremely poor in Maputo. See his "Estudo do impacto do programa de subsídio de alimentos nos idosos vulneráveis da cidade de Maputo: Uma comparação de níveis de consumo entre participantes e não-participantes" (The impact of the food subsidy program on the vulnerable elderly in the city of Maputo: A comparison of consumption levels between participants and nonparticipants) (unpublished thesis, Eduardo Mondlane University, Maputo, 1998). Besides convenience and cost of cooking fuel, bread figures prominently in the consumption bundle of the urban poor because it may be purchased in very small quantities that conform to the very low cash flow of this group. 